\title{
Some results on a tripled fixed point for nonlinear contractions in partially ordered $G$-metric spaces
}

\author{
Syed Abdul Mohiuddine and Abdullah Alotaibi*
}

\section{"Correspondence:}

mathker11@hotmail.com

Department of Mathematics,

Faculty of Science, King Abdulaziz

University, P.O. Box 80203, Jeddah,

21589, Saudi Arabia

\begin{abstract}
Berinde and Borcut (Nonlinear Anal. 74(15):4889-4897, 2011) have quite recently defined the notion of a triple fixed point and proved some interesting results related to this concept in a partially ordered metric space. In this work we prove some triple fixed point theorem for a mixed monotone mapping satisfying nonlinear contractions in the framework of a generalized metric space endowed with partial order while the idea of a generalized metric space introduced by Mustafa and Sims (J. Nonlinear Convex Anal. 7:289-297, 2006). Further we prove the uniqueness of a coupled fixed point for such a mapping in this setting.
\end{abstract}

Keywords: tripled fixed point; partially ordered set; mixed monotone mapping; generalized metric space

\section{Introduction and preliminaries}

The Banach contraction principle [1] is the most famous, simplest and one of the most versatile elementary results in fixed point theory. Fixed point theory is a very useful tool in solving a variety of problems in control theory, economic theory, nonlinear analysis and global analysis. A huge amount of literature is witnessed on applications, generalizations and extensions of this principle carried out by several authors in different directions, e.g., by weakening the hypothesis, using different setups, considering different mappings etc.

In 2006, Bhaskar and Lakshmikantham [2] initiated the study of a coupled fixed point and proved some coupled fixed point theorems for a mixed monotone operator in a partially ordered metric space. As an application of the coupled fixed point theorems, they obtained the existence and uniqueness of the solution of a periodic boundary value problem. In recent past, Lakshmikantham and Ćirić [3] determined some coupled coincidence and coupled common fixed point theorems for nonlinear contractions in partially ordered complete metric spaces. Most recently, the concept of a triple fixed point has been studied in partially ordered complete metric spaces for nonlinear contractions by Berinde and Borcut [4], who obtained the existence and uniqueness theorems for contractive type mappings in this setup which was later on studied by many authors. A large list of references can be found, for example, in the papers [5-23].

The concept of a generalized metric space was introduced and studied by Mustafa and Sims [24] and was later used to determine coupled fixed point theorems and related results by a number of authors [25-32]. We shall assume throughout this paper that the symbols

(c) 2012 Mohiuddine and Alotaibi; licensee Springer. This is an Open Access article distributed under the terms of the Creative Commons Attribution License (http://creativecommons.org/licenses/by/2.0), which permits unrestricted use, distribution, and reproduction in any medium, provided the original work is properly cited. 
$\mathbb{R}$ and $\mathbb{N}$ will denote the set of real and natural numbers respectively. Now, we recall some definitions, notations and preliminary results which we will use throughout the paper.

Given a nonempty set $X$, a mapping $G: X \times X \times X \rightarrow \mathbb{R}$ is called a generalized metric (for short, $G$-metric) on $X$ and $(X, G)$ a generalized metric space or simply a $G$-metric space if the following conditions are satisfied:

(i) $G(x, y, z)=0$ if $x=y=z$,

(ii) $G(x, x, y)>0$ for all $x, y \in X$ and $x \neq y$,

(iii) $G(x, x, y) \leq G(x, y, z)$ for all $x, y, z \in X$ and $y \neq z$,

(iv) $G(x, y, z)=G(x, z, y)=G(y, z, x)=\cdots$ (symmetry in all three variables),

(v) $G(x, y, z) \leq G(x, a, a)+G(a, y, z)$ for all $x, y, z, a \in X$ (rectangle inequality).

Example 1.1 ([24]) Let $(\mathbb{R}, d)$ be a usual metric space. Define a function $G_{s}$ by

$$
G_{s}(x, y, z)=d(x, y)+d(y, z)+d(x, z)
$$

for all $x, y, z \in \mathbb{R}$. Then $\left(\mathbb{R}, G_{s}\right)$ is a $G$-metric space.

The concepts of convergence and Cauchy sequences and continuous functions in a $G$-metric space are studied in [24].

Let $(X, G)$ be a $G$-metric space. Then a sequence $\left(x_{n}\right)$ is said to be convergent in $(X, G)$ or simply G-convergent to $x \in X$ if for every $\epsilon>0$ there exists $N \in \mathbb{N}$ such that $G\left(x_{n}, x_{m}, x\right)<\epsilon$ for all $n, m \geq N$.

Let $(X, G)$ be a $G$-metric space. Then $\left(x_{n}\right)$ is said to be Cauchy in $(X, G)$ or simply G-Cauchy if for every $\epsilon>0$ there exists $N \in \mathbb{N}$ such that $G\left(x_{n}, x_{m}, x_{k}\right)<\epsilon$ for all $n, m$, $k \geq N$. A $G$-metric space $(X, G)$ is said to be complete if every $G$-Cauchy sequence is $G$-convergent.

Let $(X, G)$ be a $G$-metric space and $f: X \rightarrow X$ be a mapping. Then $f$ is said to be G-continuous at a point $x \in X$ if and only if it is $G$-sequentially continuous at $x$; that is, whenever $\left(x_{n}\right)$ is $G$-convergent to $x$, we have $\left(f\left(x_{n}\right)\right)$ is $G$-convergent to $f(x)$.

Proposition $1.2([24])$ Let $(X, G)$ be a G-metric space and $\left(x_{n}\right)$ be a sequence in $X$. Then, for all $x \in X$, the following statements are equivalent:

(i) $\left(x_{n}\right)$ is G-convergent to $x$.

(ii) $G\left(x_{n}, x_{n}, x\right) \rightarrow 0$ as $n \rightarrow \infty$.

(iii) $G\left(x_{n}, x, x\right) \rightarrow 0$ as $n \rightarrow \infty$.

(iv) $G\left(x_{n}, x_{m}, x\right) \rightarrow 0$ as $n, m \rightarrow \infty$.

Proposition $1.3([24])$ Let $(X, G)$ be a G-metric space and $\left(x_{n}\right)$ be a sequence in $X$. Then the following statements are equivalent:

(i) $\left(x_{n}\right)$ is G-Cauchy.

(ii) For every $\epsilon>0$ there exists $N \in \mathbb{N}$ such that $G\left(x_{n}, x_{m}, x_{m}\right)<\epsilon$ for all $n, m \geq N$.

Lemma 1.4 ([24]) If $(X, G)$ is a G-metric space, then $G(x, y, y) \leq 2 G(y, x, x)$ for all $x, y \in X$.

Let $(X, G)$ be a $G$-metric space and $F: X \times X \times X \rightarrow X$ be a mapping. Then a map $F$ is said to be continuous [28] in $(X, G)$ if for every $G$-convergent sequence $x_{n} \rightarrow x, y_{n} \rightarrow y$ and $z_{n} \rightarrow z,\left(F\left(x_{n}, y_{n}, z_{n}\right)\right)$ is $G$-convergent to $F(x, y, z)$. 
Bhaskar and Lakshmikantham [2] defined and studied the concepts of a mixed monotone property and a coupled fixed point in a partially ordered metric space. Quite recently, the notions of the mixed monotone property for the mapping $F: X \times X \times X \rightarrow X$ and a tripled fixed point were introduced by Berinde and Borcut [4] as follows.

Let $(X, \leq)$ be a partially ordered set and $F: X \times X \times X \rightarrow X$ be a mapping. Then a map $F$ is said to have the mixed monotone property if $F(x, y, z)$ is monotone non-decreasing in $x$ and $z$, and is monotone non-increasing in $y$; that is, for any $x, y, z \in X$,

$$
\begin{array}{lll}
x_{1}, x_{2} \in X, x_{1} \leq x_{2} & \text { implies } & F\left(x_{1}, y, z\right) \leq F\left(x_{2}, y, z\right), \\
y_{1}, y_{2} \in X, y_{1} \leq y_{2} \quad \text { implies } & F\left(x, y_{1}, z\right) \geq F\left(x, y_{2}, z\right)
\end{array}
$$

and

$$
z_{1}, z_{2} \in X, z_{1} \leq z_{2} \quad \text { implies } \quad F\left(x, y, z_{1}\right) \leq F\left(x, y, z_{2}\right) .
$$

An element $(x, y, z) \in X \times X \times X$ is said to be a tripled fixed point of the mapping $F$ : $X \times X \times X \rightarrow X$ if

$$
F(x, y, z)=x, \quad F(y, x, y)=y \quad \text { and } \quad F(z, y, x)=z .
$$

The main results of Berinde and Borcut are as follows.

Theorem 1.5 ([4]) Let $(X, \preceq)$ be a partially ordered set and suppose there is a metric $d$ on $X$ such that $(X, d)$ is a complete metric space. Let $F: X \times X \times X \rightarrow X$ be a mapping having the mixed monotone property on $X$. Assume that there exist constants $j, k, l \in[0,1)$ with $j+k+l<1$ for which

$$
d(F(x, y, z))+d(F(u, v, w)) \leq j d(x, u)+k d(y, v)+l d(z, w)
$$

for all $x \succeq u, y \preceq v, z \succeq w$. Assume that either

(a) $F$ is continuous or

(b) $X$ has the following property:

(i) if a non-decreasing sequence $\left(x_{n}\right)$ is G-convergent to $x$, then $x_{n} \preceq x$ for all $n$,

(ii) if a non-increasing sequence $\left(y_{n}\right)$ is G-convergent to $y$, then $y_{n} \geq y$ for all $n$.

If there exist $x_{0}, y_{0}, z_{0} \in X$ such that $x_{0} \preceq F\left(x_{0}, y_{0}, z_{0}\right), y_{0} \succeq F\left(y_{0}, x_{0}, y_{0}\right)$ and $z_{0} \preceq F\left(z_{0}, y_{0}\right.$, $\left.x_{0}\right)$, then there exist $x, y, z \in X$ such that $F(x, y, z)=x, F(y, x, y)=y$ and $F(z, y, x)=z$.

Motivated by [4], we determine in this paper some triple fixed point theorems for nonlinear contractions in the framework of partially ordered generalized metric spaces and obtain uniqueness theorems for contractive type mappings in this setting.

\section{Main results}

In this section, we establish some tripled fixed point results by considering maps on generalized metric spaces endowed with partial order. Before proceeding further, first, we define the following function which will be used in our results. 
Let $\left(x_{n}\right),\left(y_{n}\right)$ and $\left(z_{n}\right)$ be any three sequences of nonnegative real numbers. Denote with $\Theta$ the set of all functions $\theta:[0, \infty)^{3} \rightarrow[0,1)$ which, satisfying $\theta\left(x_{n}, y_{n}, z_{n}\right) \rightarrow 1$, implies $x_{n}, y_{n}, z_{n} \rightarrow 0$. An example of such a function is as follows:

$$
\theta(x, y, z)= \begin{cases}\frac{\ln \left(1+k_{1} x+k_{2} y+k_{3} z\right)}{k_{1} x+k_{2} y+k_{3} z} ; & \text { at least one of } x, y, z>0 \text { and } k_{1}, k_{2}, k_{3} \in(0,1), \\ \ell \in[0,1) ; & x=0=y=z .\end{cases}
$$

Now, we are ready to prove our main results.

Theorem 2.1 Let $(X, \preceq)$ be a partially ordered set and $G$ be a G-metric on $X$ such that $(X, G)$ is a complete G-metric space. Suppose that $F: X \times X \times X \rightarrow X$ is a continuous mapping having the mixed monotone property. Assume that there exists $\theta \in \Theta$ such that

$$
\begin{aligned}
G( & F(x, y, z), F(s, t, u), F(p, q, r))+G(F(y, x, z), F(t, s, u), F(q, p, r)) \\
& +G(F(z, y, x), F(u, t, s), F(r, q, p)) \\
\leq & \theta(G(x, s, p), G(y, t, q), G(z, u, r))(G(x, s, p)+G(y, t, q)+G(z, u, r)),
\end{aligned}
$$

for all $x, y, z, s, t, u, p, q, r \in X$ with $x \succeq s \succeq p$ and $y \preceq t \preceq q$ and $z \succeq u \succeq r$, where either $s \neq p$ or $t \neq q$ or $u \neq r$. If there exist $x_{0}, y_{0}, z_{0} \in X$ such that $x_{0} \preceq F\left(x_{0}, y_{0}, z_{0}\right), y_{0} \succeq F\left(y_{0}, x_{0}, y_{0}\right)$ and $z_{0} \preceq F\left(z_{0}, y_{0}, x_{0}\right)$, then $F$ has a tripled fixed point; that is, there exist $x, y, z \in X$ such that $F(x, y, z)=x, F(y, x, y)=y$ and $F(z, y, x)=z$.

Proof Let $x_{0}, y_{0}, z_{0} \in X$ be such that $x_{0} \preceq F\left(x_{0}, y_{0}, z_{0}\right), y_{0} \succeq F\left(y_{0}, x_{0}, y_{0}\right)$ and $z_{0} \preceq F\left(z_{0}, y_{0}\right.$, $\left.x_{0}\right)$. We can choose $x_{1}, y_{1}, z_{1} \in X$ such that $x_{1}=F\left(x_{0}, y_{0}, z_{0}\right), y_{1}=F\left(y_{0}, x_{0}, y_{0}\right)$ and $z_{1}=$ $F\left(z_{0}, y_{0}, x_{0}\right)$. Write

$$
x_{n+1}=F\left(x_{n}, y_{n}, z_{n}\right), \quad y_{n+1}=F\left(y_{n}, x_{n}, y_{n}\right), \quad \text { and } \quad z_{n+1}=F\left(z_{n}, y_{n}, x_{n}\right)
$$

for all $n \geq 1$. Due to the mixed monotone property of $F$, we can find $x_{2} \succeq x_{1} \succeq x_{0}, y_{2} \preceq$ $y_{1} \preceq y_{0}$ and $z_{2} \succeq z_{1} \succeq z_{0}$. By straightforward calculation, we obtain

$$
\begin{aligned}
& x_{0} \preceq x_{1} \preceq x_{2} \preceq \cdots \preceq x_{n+1} \preceq \cdots, \\
& y_{0} \succeq y_{1} \succeq y_{2} \succeq \cdots \succeq y_{n+1} \succeq \cdots, \\
& z_{0} \preceq z_{1} \preceq z_{2} \preceq \cdots \preceq z_{n+1} \preceq \cdots .
\end{aligned}
$$

Assume that there exists a nonnegative integer $n$ such that

$$
G\left(x_{n+1}, x_{n+1}, x_{n}\right)+G\left(y_{n+1}, y_{n+1}, y_{n}\right)+G\left(z_{n+1}, z_{n+1}, z_{n}\right)=0 .
$$

It follows that

$$
G\left(x_{n+1}, x_{n+1}, x_{n}\right)=0=G\left(y_{n+1}, y_{n+1}, y_{n}\right)=G\left(z_{n+1}, z_{n+1}, z_{n}\right) .
$$

From the definition of G-metric space, we have $x_{n+1}=x_{n}, y_{n+1}=y_{n}$ and $z_{n+1}=z_{n}$. It follows from $(2.2)$ that $\left(x_{n}, y_{n}, z_{n}\right)$ is a triple fixed point of $F$. Now, we suppose that for all 
nonnegative integer $n$

$$
G\left(x_{n+1}, x_{n+1}, x_{n}\right)+G\left(y_{n+1}, y_{n+1}, y_{n}\right)+G\left(z_{n+1}, z_{n+1}, z_{n}\right) \neq 0 \text {. }
$$

Using (2.1) and (2.2), we have

$$
\begin{aligned}
& G\left(x_{n+1}, x_{n+1}, x_{n}\right)+G\left(y_{n+1}, y_{n+1}, y_{n}\right)+G\left(z_{n+1}, z_{n+1}, z_{n}\right) \\
&=G\left(F\left(x_{n}, y_{n}, z_{n}\right), F\left(x_{n}, y_{n}, z_{n}\right), F\left(x_{n-1}, y_{n-1}, z_{n-1}\right)\right) \\
& \quad+G\left(F\left(y_{n}, x_{n}, y_{n}\right), F\left(y_{n}, x_{n}, y_{n}\right), F\left(y_{n-1}, x_{n-1}, y_{n-1}\right)\right) \\
& \quad+G\left(F\left(z_{n}, y_{n}, x_{n}\right), F\left(z_{n}, y_{n}, x_{n}\right), F\left(z_{n-1}, y_{n-1}, x_{n-1}\right)\right) \\
& \leq \theta\left(G\left(x_{n}, x_{n}, x_{n-1}\right), G\left(y_{n}, y_{n}, y_{n-1}\right), G\left(z_{n}, z_{n}, z_{n-1}\right)\right) \\
& \times\left(G\left(x_{n}, x_{n}, x_{n-1}\right)+G\left(y_{n}, y_{n}, y_{n-1}\right)+G\left(z_{n}, z_{n}, z_{n-1}\right)\right),
\end{aligned}
$$

which implies

$$
\begin{gathered}
G\left(x_{n+1}, x_{n+1}, x_{n}\right)+G\left(y_{n+1}, y_{n+1}, y_{n}\right)+G\left(z_{n+1}, z_{n+1}, z_{n}\right) \\
<G\left(x_{n}, x_{n}, x_{n-1}\right)+G\left(y_{n}, y_{n}, y_{n-1}\right)+G\left(z_{n}, z_{n}, z_{n-1}\right) .
\end{gathered}
$$

For all $n \in \mathbb{N}$, write

$$
\gamma_{n}=G\left(x_{n+1}, x_{n+1}, x_{n}\right)+G\left(y_{n+1}, y_{n+1}, y_{n}\right)+G\left(z_{n+1}, z_{n+1}, z_{n}\right),
$$

then a sequence $\left(\gamma_{n}\right)$ is monotone decreasing. Therefore, there exists some $\gamma \geq 0$ such that

$$
\lim _{n \rightarrow \infty} \gamma_{n}=\lim _{n \rightarrow \infty}\left[G\left(x_{n+1}, x_{n+1}, x_{n}\right)+G\left(y_{n+1}, y_{n+1}, y_{n}\right)+G\left(z_{n+1}, z_{n+1}, z_{n}\right)\right]=\gamma
$$

We shall claim that $\gamma=0$. On the contrary, suppose that $\gamma>0$, we have from $(2.3)$

$$
\begin{aligned}
& \frac{G\left(x_{n+1}, x_{n+1}, x_{n}\right)+G\left(y_{n+1}, y_{n+1}, y_{n}\right)+G\left(z_{n+1}, z_{n+1}, z_{n}\right)}{G\left(x_{n}, x_{n}, x_{n-1}\right)+G\left(y_{n}, y_{n}, y_{n-1}\right)+G\left(z_{n}, z_{n}, z_{n-1}\right)} \\
& \quad \leq \theta\left(G\left(x_{n}, x_{n}, x_{n-1}\right)+G\left(y_{n}, y_{n}, y_{n-1}\right)+G\left(z_{n}, z_{n}, z_{n-1}\right)\right)<1 .
\end{aligned}
$$

Letting $n \rightarrow \infty$, we get

$$
\theta\left(G\left(x_{n}, x_{n}, x_{n-1}\right)+G\left(y_{n}, y_{n}, y_{n-1}\right)+G\left(z_{n}, z_{n}, z_{n-1}\right)\right) \rightarrow 1
$$

Using the property of the function $\theta$, we have

$$
G\left(x_{n}, x_{n}, x_{n-1}\right), G\left(y_{n}, y_{n}, y_{n-1}\right), G\left(z_{n}, z_{n}, z_{n-1}\right) \rightarrow 0 \quad \text { as } n \rightarrow \infty \text {. }
$$

So, we have

$$
G\left(x_{n}, x_{n}, x_{n-1}\right)+G\left(y_{n}, y_{n}, y_{n-1}\right)+G\left(z_{n}, z_{n}, z_{n-1}\right) \rightarrow 0 \quad \text { as } n \rightarrow \infty \text {, }
$$


which is a contradiction in virtue of (2.5). Thus, $\gamma=0$. From (2.4) we have

$$
G\left(x_{n+1}, x_{n+1}, x_{n}\right)+G\left(y_{n+1}, y_{n+1}, y_{n}\right)+G\left(z_{n+1}, z_{n+1}, z_{n}\right) \rightarrow 0
$$

Now, we have to show that $\left(x_{n}\right),\left(y_{n}\right)$ and $\left(z_{n}\right)$ are Cauchy sequences in the $G$-metric space $(X, G)$. On the contrary, suppose that at least one of $\left(x_{n}\right),\left(y_{n}\right)$ or $\left(z_{n}\right)$ is not a Cauchy sequence in $(X, G)$. Then there exists $\epsilon>0$ for which we can find subsequences $\left(x_{k(j)}\right),\left(x_{l(j)}\right)$ of $\left(x_{n}\right) ;\left(y_{k(j)}\right),\left(y_{l(j)}\right)$ of $\left(y_{n}\right)$ and $\left(z_{k(j)}\right),\left(z_{l(j)}\right)$ of the sequence $\left(z_{n}\right)$ with $k(j)>l(j) \geq j$ for all $j \in \mathbb{N}$ such that

$$
\alpha_{j}=G\left(x_{k(j)}, x_{k(j)}, x_{l(j)}\right)+G\left(y_{k(j)}, y_{k(j)}, y_{l(j)}\right)+G\left(z_{k(j)}, z_{k(j)}, z_{l(j)}\right) \geq \epsilon .
$$

We may also assume

$$
G\left(x_{k(j)-1}, x_{k(j)-1}, x_{l(j)}\right)+G\left(y_{k(j)-1}, y_{k(j)-1}, y_{l(j)}\right)+G\left(z_{k(j)-1}, z_{k(j)-1}, z_{l(j)}\right)<\epsilon,
$$

by choosing $k(j)$ to be the smallest number exceeding $l(j)$ for which (2.7) holds. From (2.7) and (2.8), and using the rectangle inequality, we obtain

$$
\begin{aligned}
\epsilon \leq & \alpha_{j}=G\left(x_{k(j)}, x_{k(j)}, x_{l(j)}\right)+G\left(y_{k(j)}, y_{k(j)}, y_{l(j)}\right)+G\left(z_{k(j)}, z_{k(j)}, z_{l(j)}\right) \\
\leq & G\left(x_{k(j)}, x_{k(j)}, x_{k(j)-1}\right)+G\left(x_{k(j)-1}, x_{k(j)-1}, x_{l(j)}\right)+G\left(y_{k(j)}, y_{k(j)}, y_{k(j)-1}\right) \\
& +G\left(y_{k(j)-1}, y_{k(j)-1}, y_{l(j)}\right)+G\left(z_{k(j)}, z_{k(j)}, z_{k(j)-1}\right)+G\left(z_{k(j)-1}, z_{k(j)-1}, z_{l(j)}\right) \\
< & G\left(x_{k(j)}, x_{k(j)}, x_{k(j)-1}\right)+G\left(y_{k(j)}, y_{k(j)}, y_{k(j)-1}\right)+G\left(z_{k(j)}, z_{k(j)}, z_{k(j)-1}\right)+\epsilon .
\end{aligned}
$$

Letting $j \rightarrow \infty$ in the above inequality and using (2.6), we get

$$
\alpha_{j}=G\left(x_{k(j)}, x_{k(j)}, x_{l(j)}\right)+G\left(y_{k(j)}, y_{k(j)}, y_{l(j)}\right)+G\left(z_{k(j)}, z_{k(j)}, z_{l(j)}\right) \rightarrow \epsilon .
$$

Again, by using the rectangle inequality, we obtain

$$
\begin{aligned}
\alpha_{j}= & G\left(x_{k(j)}, x_{k(j)}, x_{l(j)}\right)+G\left(y_{k(j)}, y_{k(j)}, y_{l(j)}\right)+G\left(z_{k(j)}, z_{k(j)}, z_{l(j)}\right) \\
\leq & G\left(x_{k(j)}, x_{k(j)}, x_{k(j)+1}\right)+G\left(x_{k(j)+1}, x_{k(j)+1}, x_{l(j)+1}\right)+G\left(x_{l(j)+1}, x_{l(j)+1}, x_{l(j)}\right) \\
& +G\left(y_{k(j)}, y_{k(j)}, y_{k(j)+1}\right)+G\left(y_{k(j)+1}, y_{k(j)+1}, y_{l(j)+1}\right)+G\left(y_{l(j)+1}, y_{l(j)+1}, y_{l(j)}\right) \\
& +G\left(z_{k(j)}, z_{k(j)}, z_{k(j)+1}\right)+G\left(z_{k(j)+1}, z_{k(j)+1}, z_{l(j)+1}\right)+G\left(z_{l(j)+1}, z_{l(j)+1}, z_{l(j)}\right) \\
= & \gamma_{l(j)}+G\left(x_{k(j)}, x_{k(j)}, x_{k(j)+1}\right)+G\left(x_{k(j)+1}, x_{k(j)+1}, x_{l(j)+1}\right)+G\left(y_{k(j)}, y_{k(j)}, y_{k(j)+1}\right) \\
& +G\left(y_{k(j)+1}, y_{k(j)+1}, y_{l(j)+1}\right)+G\left(z_{k(j)}, z_{k(j)}, z_{k(j)+1}\right)+G\left(z_{k(j)+1}, z_{k(j)+1}, z_{l(j)+1}\right) .
\end{aligned}
$$

By using Lemma 1.4, the above inequality becomes

$$
\begin{aligned}
\alpha_{j} \leq & \gamma_{l(j)}+2 G\left(x_{k(j)+1}, x_{k(j)+1}, x_{k(j)}\right)+2 G\left(y_{k(j)+1}, y_{k(j)+1}, y_{k(j)}\right)+2 G\left(z_{k(j)+1}, z_{k(j)+1}, z_{k(j)}\right) \\
& +G\left(x_{k(j)+1}, x_{k(j)+1}, x_{l(j)+1}\right)+G\left(y_{k(j)+1}, y_{k(j)+1}, y_{l(j)+1}\right)+G\left(z_{k(j)+1}, z_{k(j)+1}, z_{l(j)+1}\right) .
\end{aligned}
$$


This implies

$$
\begin{aligned}
\alpha_{j} \leq & \gamma_{l(j)}+2 \gamma_{k(j)}+G\left(x_{k(j)+1}, x_{k(j)+1}, x_{l(j)+1}\right) \\
& +G\left(y_{k(j)+1}, y_{k(j)+1}, y_{l(j)+1}\right)+G\left(z_{k(j)+1}, z_{k(j)+1}, z_{l(j)+1}\right) .
\end{aligned}
$$

Using (2.1) and (2.2), (2.10) becomes

$$
\begin{aligned}
\alpha_{j} \leq & \gamma_{l(j)}+2 \gamma_{k(j)}+G\left(F\left(x_{k(j)}, y_{k(j)}, z_{k(j)}\right), F\left(x_{k(j)}, y_{k(j)}, z_{k(j)}\right), F\left(x_{l(j)}, y_{l(j)}, z_{l(j)}\right)\right) \\
& +G\left(F\left(y_{k(j)}, x_{k(j)}, y_{k(j)}\right), F\left(y_{k(j)}, x_{k(j)}, y_{k(j)}\right), F\left(y_{l(j)}, x_{l(j)}, y_{l(j)}\right)\right) \\
& +G\left(F\left(z_{k(j)}, y_{k(j)}, x_{k(j)}\right), F\left(z_{k(j)}, y_{k(j)}, x_{k(j)}\right), F\left(z_{l(j)}, y_{l(j)}, x_{l(j)}\right)\right) \\
\leq & \theta\left(G\left(x_{k(j)}, x_{k(j)}, x_{l(j)}\right), G\left(y_{k(j)}, y_{k(j)}, y_{l(j)}\right), G\left(z_{k(j)}, z_{k(j)}, z_{l(j)}\right)\right)\left(G\left(x_{k(j)}, x_{k(j)}, x_{l(j)}\right)\right. \\
& \left.+G\left(y_{k(j)}, y_{k(j)}, y_{l(j)}\right)+G\left(z_{k(j)}, z_{k(j)}, z_{l(j)}\right)\right)+\gamma_{l(j)}+2 \gamma_{k(j)} \\
= & \theta\left(G\left(x_{k(j)}, x_{k(j)}, x_{l(j)}\right), G\left(y_{k(j)}, y_{k(j)}, y_{l(j)}\right), G\left(z_{k(j)}, z_{k(j)}, z_{l(j)}\right)\right) \alpha_{j}+\gamma_{l(j)}+2 \gamma_{k(j)} .
\end{aligned}
$$

It follows that

$$
\frac{\alpha_{j}-\gamma_{l(j)}-2 \gamma_{k(j)}}{\alpha_{j}} \leq \theta\left(G\left(x_{k(j)}, x_{k(j)}, x_{l(j)}\right), G\left(y_{k(j)}, y_{k(j)}, y_{l(j)}\right), G\left(z_{k(j)}, z_{k(j)}, z_{l(j)}\right)\right)<1
$$

Taking the limit as $j \rightarrow \infty$, we obtain

$$
\theta\left(G\left(x_{k(j)}, x_{k(j)}, x_{l(j)}\right), G\left(y_{k(j)}, y_{k(j)}, y_{l(j)}\right), G\left(z_{k(j)}, z_{k(j)}, z_{l(j)}\right)\right) \rightarrow 1 .
$$

Using the property $\theta\left(x_{n}, y_{n}\right) \rightarrow 1$ implies $x_{n}, y_{n} \rightarrow 0$, we get

$$
G\left(x_{k(j)}, x_{k(j)}, x_{l(j)}\right), G\left(y_{k(j)}, y_{k(j)}, y_{l(j)}\right), G\left(z_{k(j)}, z_{k(j)}, z_{l(j)}\right) \rightarrow 0 \text {. }
$$

Therefore, $\alpha_{j} \rightarrow 0$, which is a contradiction and hence $\left(x_{n}\right),\left(y_{n}\right)$ and $\left(z_{n}\right)$ are Cauchy sequences in the $G$-metric space $(X, G)$. Since $(X, G)$ is a complete $G$-metric space, hence $\left(x_{n}\right),\left(y_{n}\right)$ and $\left(z_{n}\right)$ are $G$-convergent. Then there exist $x, y, z \in X$ such that $\left(x_{n}\right),\left(y_{n}\right)$ and $\left(z_{n}\right)$ are $G$-convergent to $x, y$ and $z$ respectively. Since $F$ is continuous. Letting $n \rightarrow \infty$ in (2.2), we get $x=F(x, y, z), y=F(y, x, y)$ and $z=F(z, y, x)$. Thus, we conclude that $F$ has a tripled fixed point.

Theorem 2.2 Let $(X, \preceq)$ be a partially ordered set and $G$ be a G-metric on $X$ such that $(X, G)$ is a complete $G$-metric space. Suppose that there exist $\theta \in \Theta$ and a mapping $F$ : $X \times X \times X \rightarrow X$ having the mixed monotone property such that

$$
\begin{aligned}
G( & F(x, y, z), F(s, t, u), F(p, q, r))+G(F(y, x, z), F(t, s, u), F(q, p, r)) \\
& +G(F(z, y, x), F(u, t, s), F(r, q, p)) \\
\leq & \theta(G(x, s, p), G(y, t, q), G(z, u, r))(G(x, s, p)+G(y, t, q)+G(z, u, r)),
\end{aligned}
$$

for all $x, y, z, s, t, u, p, q, r \in X$ with $x \succeq s \succeq p, y \preceq t \preceq q$ and $z \succeq u \succeq r$ where either $s \neq p$ or $t \neq q$ or $u \neq r$. Assume that $X$ has the following property: 
(i) if a non-decreasing sequence $\left(x_{n}\right)$ is G-convergent to $x\left(\left(z_{n}\right)\right.$ is G-convergent to $\left.z\right)$, then $x_{n} \preceq x\left(z_{n} \preceq x\right.$ respectively) for all $n$,

(ii) if a non-increasing sequence $\left(y_{n}\right)$ is G-convergent to $y$, then $y_{n} \succeq y$ for all $n$. If there exist $x_{0}, y_{0}, z_{0} \in X$ such that $x_{0} \preceq F\left(x_{0}, y_{0}, z_{0}\right), y_{0} \succeq F\left(y_{0}, x_{0}, y_{0}\right)$ and $z_{0} \preceq F\left(z_{0}, y_{0}, x_{0}\right)$ then $F$ has a triple fixed point.

Proof Proceeding along the same lines as in Theorem 2.1, we obtain a non-decreasing sequence $\left(x_{n}\right)$ converges to $x$, a non-increasing sequence $\left(y_{n}\right)$ converges to $y$ and a nondecreasing sequence $\left(z_{n}\right)$ converges to $z$ for some $x, y, z \in X$. Since $x_{n} \preceq x, y_{n} \succeq y$ and $z_{n} \preceq z$ for all $n$. If $x_{n}=x, y_{n}=y$ and $z_{n}=z$ for some $n \geq 0$, then by construction, $x_{n+1}=x, y_{n+1}=y$ and $z_{n+1}=z$. Thus, $(x, y, z)$ is a tripled fixed point of $F$. So, we assume either $x_{n} \neq x$ or $y_{n} \neq y$ or $z_{n} \neq z$ for all $n \geq 0$. Then by using (2.11) and the rectangle inequality, we have

$$
\begin{aligned}
& G(F(x, y, z), x, x)+G(F(y, x, y), y, y)+G(F(z, y, x), z, z) \\
& \leq G\left(F(x, y, z), F\left(x_{n}, y_{n}, z_{n}\right), F\left(x_{n}, y_{n}, z_{n}\right)\right)+G\left(F\left(x_{n}, y_{n}, z_{n}\right), x, x\right) \\
&+G\left(F(y, x, y), F\left(y_{n}, x_{n}, y_{n}\right), F\left(y_{n}, x_{n}, y_{n}\right)\right)+G\left(F\left(y_{n}, x_{n}, y_{n}\right), y, y\right) \\
&+G\left(F(z, y, x), F\left(z_{n}, y_{n}, x_{n}\right), F\left(z_{n}, y_{n}, x_{n}\right)\right)+G\left(F\left(z_{n}, y_{n}, x_{n}\right), z, z\right) \\
&= G\left(F\left(x_{n}, y_{n}, z_{n}\right), F\left(x_{n}, y_{n}, z_{n}\right), F(x, y, z)\right)+G\left(x_{n+1}, x, x\right) \\
&+G\left(F\left(y_{n}, x_{n}, y_{n}\right), F\left(y_{n}, x_{n}, y_{n}\right), F(y, x, y)\right)+G\left(y_{n+1}, y, y\right) \\
&+G\left(F\left(z_{n}, y_{n}, x_{n}\right), F\left(z_{n}, y_{n}, x_{n}\right), F(z, y, x)\right)+G\left(z_{n+1}, z, z\right) \\
& \leq \theta\left(G\left(x_{n}, x_{n}, x\right), G\left(y_{n}, y_{n}, y\right), G\left(z_{n}, z_{n}, z\right)\right)\left(G\left(x_{n}, x_{n}, x\right)+G\left(y_{n}, y_{n}, y\right)\right. \\
&\left.+G\left(z_{n}, z_{n}, z\right)\right)+G\left(x_{n+1}, x, x\right)+G\left(y_{n+1}, y, y\right)+G\left(z_{n+1}, z, z\right) \\
&< G\left(x_{n}, x_{n}, x\right)+G\left(y_{n}, y_{n}, y\right)+G\left(z_{n}, z_{n}, z\right)+G\left(x_{n+1}, x, x\right)+G\left(y_{n+1}, y, y\right)+G\left(z_{n+1}, z, z\right) .
\end{aligned}
$$

Letting $n \rightarrow \infty$ in the above equation, we get

$$
G(F(x, y, z), x, x)+G(F(y, x, z), y, y)+G(F(z, y, x), z, z)=0 .
$$

Thus, $x=F(x, y, z), y=F(y, x, z)$ and $z=F(z, y, x)$ and hence $(x, y, z)$ is a tripled fixed point of $F$.

Corollary 2.3 Let $(X, \preceq)$ be a partially ordered set and $G$ be a G-metric on $X$ such that $(X, G)$ is a complete $G$-metric space. Suppose that $F: X \times X \times X \rightarrow X$ is a mapping having the mixed monotone property and assume that there exists $\mu \in \Theta$ such that

$$
\begin{aligned}
& G(F(x, y, z), F(s, t, u), F(p, q, r)) \\
& \quad \leq \frac{1}{3} \mu(G(x, s, p), G(y, t, q), G(z, u, r))(G(x, s, p)+G(y, t, q)+G(z, u, r))
\end{aligned}
$$

for all $x, y, z, s, t, u, p, q, r \in X$ with $x \succeq s \succeq p, y \preceq t \preceq q$ and $z \succeq u \succeq r$, where either $s \neq p$ or $t \neq q$ or $u \neq r$. Suppose that either

(a) $F$ is continuous or

(b) $X$ has the following property: 
(i) if a non-decreasing sequence $\left(x_{n}\right)$ is G-convergent to $x\left(\left(z_{n}\right)\right.$ is G-convergent to $\left.z\right)$, then $x_{n} \preceq x\left(z_{n} \preceq x\right.$ respectively) for all $n$,

(ii) if a non-increasing sequence $\left(y_{n}\right)$ is G-convergent to $y$, then $y_{n} \succeq y$ for all $n$.

If there exist $x_{0}, y_{0}, z_{0} \in X$ such that $x_{0} \preceq F\left(x_{0}, y_{0}, z_{0}\right), y_{0} \succeq F\left(y_{0}, x_{0}, y_{0}\right)$ and $z_{0} \preceq F\left(z_{0}, y_{0}\right.$, $\left.x_{0}\right)$, then $F$ has a triple fixed point.

Proof For all $x, y, z, s, t, u, p, q, r \in X$, write

$$
\begin{aligned}
& G(F(y, x, z), F(t, s, u), F(q, p, r)) \\
& \quad \leq \frac{1}{3} \mu(G(y, t, q), G(x, s, p), G(z, u, r))(G(y, t, q)+G(x, s, p)+G(z, u, r)), \\
& G(F(z, y, x), F(u, t, s), F(r, q, p)) \\
& \quad \leq \frac{1}{3} \mu(G(z, u, r), G(y, t, q), G(x, s, p))(G(z, u, r)+G(y, t, q)+G(x, s, p)) .
\end{aligned}
$$

Adding (2.12), (2.13) and (2.14), we get

$$
\begin{aligned}
G( & F(x, y, z), F(s, t, u), F(p, q, r))+G(F(y, x, z), F(t, s, u), F(q, p, r)) \\
& +G(F(z, y, x), F(u, t, s), F(r, q, p)) \\
\leq & \frac{1}{3}[\mu(G(x, s, p), G(y, t, q), G(z, u, r))+\mu(G(y, t, q), G(x, s, p), G(z, u, r)) \\
& +\mu(G(z, u, r), G(y, t, q), G(x, s, p))](G(x, s, p)+G(y, t, q)+G(z, u, r)) \\
= & \theta(G(x, s, p), G(y, t, q), G(z, u, r))(G(x, s, p)+G(y, t, q)+G(z, u, r)),
\end{aligned}
$$

where $\theta\left(\beta_{1}, \beta_{2}, \beta_{3}\right)=\frac{1}{3}\left[\mu\left(\beta_{1}, \beta_{2}, \beta_{3}\right)+\mu\left(\beta_{2}, \beta_{1}, \beta_{3}\right)+\mu\left(\beta_{3}, \beta_{2}, \beta_{1}\right)\right]$ for all $\beta_{1}, \beta_{2}, \beta_{3} \in[0, \infty)$. It is easy to verify that $\theta \in \Theta$. Applying Theorems 2.1 and 2.2 , we get the desired result.

Corollary 2.4 Let $(X, \preceq)$ be a partially ordered set and $G$ be a G-metric on $X$ such that $(X, G)$ is a complete $G$-metric space. Suppose that $F: X \times X \times X \rightarrow X$ is a mapping having a mixed monotone property and assume that there exists $k \in[0,1)$ such that

$$
G(F(x, y, z), F(s, t, u), F(p, q, r)) \leq \frac{k}{3}(G(x, s, p)+G(y, t, q)+G(z, u, r))
$$

for all $x, y, z, s, t, u, p, q, r \in X$ with $x \succeq s \succeq p, y \preceq t \preceq q$ and $z \succeq u \succeq r$, where either $s \neq p$ or $t \neq q$ or $u \neq r$. Suppose that either

(a) $F$ is continuous or

(b) $X$ has the following property:

(i) if a non-decreasing sequence $\left(x_{n}\right)$ is G-convergent to $x\left(\left(z_{n}\right)\right.$ is G-convergent to $\left.z\right)$, then $x_{n} \preceq x\left(z_{n} \preceq x\right.$ respectively) for all $n$,

(ii) if a non-increasing sequence $\left(y_{n}\right)$ is G-convergent to $y$, then $y_{n} \succeq y$ for all $n$.

If there exist $x_{0}, y_{0}, z_{0} \in X$ such that $x_{0} \preceq F\left(x_{0}, y_{0}, z_{0}\right), y_{0} \succeq F\left(y_{0}, x_{0}, y_{0}\right)$ and $z_{0} \preceq F\left(z_{0}, y_{0}\right.$, $\left.x_{0}\right)$, then $F$ has a triple fixed point.

Proof Taking $\mu\left(\beta_{1}, \beta_{2}, \beta_{3}\right)=k$ in Theorems 2.1 and 2.2 for all $\beta_{1}, \beta_{2}, \beta_{3} \in[0, \infty)$ and $k \in$ $[0,1)$, we get the desired result. 
Remark 2.5 To assure the uniqueness of a coupled fixed point, we shall consider the following condition: If $(Y, \preceq)$ is a partially ordered set, we endow the product $Y \times Y \times Y$ with

$$
(x, y, z) \preceq(u, v, w) \quad \text { if and only if } \quad x \preceq u, y \succeq v, z \preceq w \text {, }
$$

for all $(x, y, z),(u, v, w) \in Y \times Y \times Y$.

Theorem 2.6 In addition to the hypothesis of Theorem 2.1, suppose that for all $(x, y, z),(s, t$, $u) \in X \times X \times X$, there exists $(p, q, r) \in X \times X \times X$ that is comparable with $(x, y, z)$ and $(s, t, u)$. Then $F$ has a unique triple fixed point.

Proof It follows from Theorem 2.1 that the set of coupled fixed points is nonempty. Suppose $(x, y, z)$ and $(s, t, u)$ are triple fixed points of the mapping $F: X \times X \times X \rightarrow X$; that is, $x=F(x, y, z), y=F(y, x, y), z=F(z, y, x), s=F(s, t, u), t=F(t, s, t)$ and $u=F(u, t, s)$. We shall now show that $x=s, y=t$ and $z=u$. By assumption, there exists $(p, q, r)$ in $X \times X \times X$ that is comparable to $(x, y, z)$ and $(s, t, u)$. Put $p=p_{0}, q=q_{0}$ and $r=r_{0}$, and choose $p_{1}, q_{1}, r_{1} \in X$ such that $p_{1}=F\left(p_{1}, q_{1}, r_{1}\right), q_{1}=F\left(q_{1}, p_{1}, q_{1}\right)$ and $r_{1}=F\left(r_{1}, q_{1}, p_{1}\right)$. Thus, we can define three sequences $\left(p_{n}\right),\left(q_{n}\right)$ and $\left(r_{n}\right)$ as

$$
p_{n}=F\left(p_{n-1}, q_{n-1}, r_{n-1}\right), \quad q_{n}=F\left(q_{n-1}, p_{n-1}, q_{n-1}\right) \quad \text { and } \quad r_{n}=F\left(r_{n-1}, q_{n-1}, p_{n-1}\right) .
$$

Since $(p, q, r)$ is comparable to $(x, y, z)$, we can assume that $(x, y, z) \succeq(p, q, r)=\left(p_{0}, q_{0}, r_{0}\right)$. Then it is easy to show that $\left(p_{n}, q_{n}, r_{n}\right)$ and $(x, y, z)$ are comparable; that is, $(x, y, z) \succeq$ $\left(p_{n}, q_{n}, r_{n}\right)$ for all $n$. Thus, from (2.1) we have

$$
\begin{aligned}
& G\left(p_{n}, x, x\right)+G\left(q_{n}, y, y\right)+G\left(r_{n}, z, z\right) \\
&= G\left(F\left(p_{n-1}, q_{n-1}, r_{n-1}\right), F(x, y, z), F(x, y, z)\right) \\
&+G\left(F\left(q_{n-1}, p_{n-1}, q_{n-1}\right), F(y, x, y), F(y, x, y)\right) \\
&+G\left(F\left(r_{n-1}, q_{n-1}, p_{n-1}\right), F(z, y, x), F(z, y, x)\right) \\
& \leq \theta\left(G\left(p_{n-1}, x, x\right), G\left(q_{n-1}, y, y\right), G\left(r_{n-1}, z, z\right)\right) \\
& \times\left(G\left(p_{n-1}, x, x\right)+G\left(q_{n-1}, y, y\right)+G\left(r_{n-1}, z, z\right)\right),
\end{aligned}
$$

which implies

$$
G\left(p_{n}, x, x\right)+G\left(q_{n}, y, y\right)+G\left(r_{n}, z, z\right)<G\left(p_{n-1}, x, x\right)+G\left(q_{n-1}, y, y\right)+G\left(r_{n-1}, z, z\right) .
$$

We see that the sequence $\left(G\left(p_{n}, x, x\right)+G\left(q_{n}, y, y\right)+G\left(r_{n}, z, z\right)\right)$ is decreasing, there exists some $\xi \geq 0$ such that

$$
G\left(p_{n}, x, x\right)+G\left(q_{n}, y, y\right)+G\left(r_{n}, z, z\right) \rightarrow \xi \quad \text { as } n \rightarrow \infty .
$$

Now, we have to show that $\xi=0$. On the contrary, suppose that $\xi>0$. Following the same arguments as in the proof of Theorem 2.1, we obtain

$$
\theta\left(G\left(p_{n-1}, x, x\right), G\left(q_{n-1}, y, y\right), G\left(r_{n-1}, z, z\right)\right) \rightarrow 1 .
$$


It follows that

$$
G\left(p_{n-1}, x, x\right), G\left(q_{n-1}, y, y\right), G\left(r_{n-1}, z, z\right) \rightarrow 0 .
$$

This implies that

$$
G\left(p_{n-1}, x, x\right)+G\left(q_{n-1}, y, y\right)+G\left(r_{n-1}, z, z\right) \rightarrow 0,
$$

which is not possible in virtue of (2.15). Hence, $\xi=0$. Therefore, (2.17) becomes

$$
G\left(p_{n}, x, x\right)+G\left(q_{n}, y, y\right)+G\left(r_{n}, z, z\right) \rightarrow 0 \quad \text { as } n \rightarrow \infty .
$$

Similarly, we can show that

$$
\begin{aligned}
& G\left(p_{n}, s, s\right)+G\left(q_{n}, t, t\right)+G\left(r_{n}, u, u\right) \rightarrow 0 \quad \text { as } n \rightarrow \infty ; \\
& G\left(p_{n}, p_{n}, x\right)+G\left(q_{n}, q_{n}, y\right)+G\left(r_{n}, r_{n}, z\right) \rightarrow 0 \quad \text { as } n \rightarrow \infty ; \\
& G\left(p_{n}, p_{n}, s\right)+G\left(q_{n}, q_{n}, t\right)+G\left(r_{n}, r_{n}, u\right) \rightarrow 0 \quad \text { as } n \rightarrow \infty .
\end{aligned}
$$

Using (2.18)-(2.21), the rectangle inequality and taking the limit $n \rightarrow \infty$, we obtain $G(s, x, x)+G(t, y, y)+G(u, z, z)=0$. Thus, we conclude that $x=s, y=t$ and $z=u$. Hence, $F$ has a unique triple fixed point.

Similarly, we can prove the following statement:

Theorem 2.7 In addition to the hypothesis of Theorem 2.2, suppose that for all $(x, y, z),(s, t$, $u) \in X \times X \times X$, there exists $(p, q, r) \in X \times X \times X$ that is comparable with $(x, y, z)$ and $(s, t, u)$. Then $F$ has a unique triple fixed point.

\section{Competing interests}

The authors declare that they have no competing interests.

\section{Authors' contributions}

The authors contributed equally and significantly in writing this paper. Both authors read and approved the final manuscript.

\section{Acknowledgements}

The authors have benefited from the reports of the anonymous referees, and they are thankful for their valuable comments on the first draft of this paper which improved the presentation and readability.

\section{Received: 13 April 2012 Accepted: 2 October 2012 Published: 17 October 2012}

\section{References}

1. Banach, S: Sur les opérations dans les ensembles abstraits et leur application aux équations intégrales. Fundam. Math. 3, 133-181 (1922)

2. Bhaskar, TG, Lakshmikantham, V: Fixed point theorems in partially ordered metric spaces and applications. Nonlinear Anal. 65, 1379-1393 (2006)

3. Lakshmikantham, V, Ćirić, L: Coupled fixed point theorems for nonlinear contractions in partially ordered metric spaces. Nonlinear Anal. 70, 4341-4349 (2009)

4. Berinde, $\mathrm{V}$, Borcut, M: Tripled fixed point theorems for contractive type mappings in partially ordered metric spaces. Nonlinear Anal. 74(15), 4889-4897 (2011)

5. Abbas, M, Nazir, T, Radenović, S: Fixed points of four maps in partially ordered metric spaces. Appl. Math. Lett. 24 1520-1526 (2011)

6. Abbas, M, Khan, AR, Nazir, T: Coupled common fixed point results in two generalized metric spaces. Appl. Math. Comput. 217, 6328-6336 (2011) 
7. Agarwal, RP, El-Gebeily, MA, O’Regan, D: Generalized contractions in partially ordered metric spaces. Appl. Anal. 87, 109-116(2008)

8. Altun, I, Erduran, A: Fixed point theorems for monotone mappings on partial metric spaces. Fixed Point Theory Appl. 2011, Article ID 508730 (2011)

9. Altun, I, Sola, F, Simsek, H: Generalized contractions on partial metric spaces. Topol. Appl. 157, 2778-2785 (2010)

10. Aydi, H, Karapinar, E, Postolache, M: Tripled coincidence point theorems for weak $\varphi$-contractions in partially ordered metric spaces. Fixed Point Theory Appl. 2012, 44 (2012)

11. Berzig, M, Samet, B: An extension of coupled fixed point's concept in higher dimension and applications. Comput. Math. Appl. 63, 1319-1334 (2012)

12. Choudhury, BS, Kundu, A: A coupled coincidence point result in partially ordered metric spaces for compatible mappings. Nonlinear Anal. 73, 2524-2531 (2010)

13. Ćirić, L, Cakić, N, Rajović, M, Ume, JS: Monotone generalized nonlinear contractions in partially ordered metric spaces. Fixed Point Theory Appl. 2008, Article ID 131294 (2008)

14. Karapinar, E: Coupled fixed point theorems for nonlinear contractions in cone metric spaces. Comput. Math. Appl. 59, 3656-3668 (2010)

15. Luong, NV, Thuan, NX: Coupled fixed points in partially ordered metric spaces and application. Nonlinear Anal. 74 983-992 (2011)

16. Nashine, HK, Kadelburg, Z, Radenović, S: Coupled common fixed point theorems for $w^{*}$-compatible mappings in ordered cone metric spaces. Appl. Math. Comput. 218, 5422-5432 (2012)

17. Nashine, HK, Shatanawi, W: Coupled common fixed point theorems for a pair of commuting mappings in partially ordered complete metric spaces. Comput. Math. Appl. 62, 1984-1993 (2011)

18. Nashine, HK, Samet, B: Fixed point results for mappings satisfying $(\psi, \varphi)$-weakly contractive condition in partially ordered metric spaces. Nonlinear Anal. 74, 2201-2209 (2011)

19. Nieto, JJ, Rodríguez-López, R: Contractive mapping theorems in partially ordered sets and applications to ordinary differential equations. Order 22, 223-239 (2005)

20. Nieto, JJ, Rodriguez-López, R: Existence and uniqueness of fixed point in partially ordered sets and applications to ordinary differential equations. Acta Math. Sin. Engl. Ser. 23(12), 2205-2212 (2007)

21. Ran, ACM, Reurings, MCB: A fixed point theorem in partially ordered sets and some applications to matrix equations. Proc. Am. Math. Soc. 132, 1435-1443 (2004)

22. Samet, B: Coupled fixed point theorems for a generalized Meir-Keeler contraction in partially ordered metric spaces. Nonlinear Anal. 72, 4508-4517 (2010)

23. Sintunavarat, W, Cho, YJ, Kumam, P: Common fixed point theorems for c-distance in ordered cone metric spaces. Comput. Math. Appl. 62, 1969-1978 (2011)

24. Mustafa, Z, Sims, B: A new approach to generalized metric spaces. J. Nonlinear Convex Anal. 7(2), 289-297 (2006)

25. Mustafa, Z, Obiedat, H, Awawdeh, F: Some fixed point theorem for mapping on complete G-metric spaces. Fixed Point Theory Appl. 2008, Article ID 189870 (2008)

26. Abbas, M, Sintunavarat, W, Kumam, P: Coupled fixed point of generalized contractive mappings on partially ordered G-metric spaces. Fixed Point Theory Appl. 2012, 31 (2012)

27. Aydi, H, Damjanović, B, Samet, B, Shatanawi, W: Coupled fixed point theorems for nonlinear contractions in partially ordered G-metric spaces. Math. Comput. Model. 54, 2443-2450 (2011)

28. Choudhury, BS, Maity, P: Coupled fixed point results in generalized metric spaces. Math. Comput. Model. 54, 73-79 (2011)

29. Luong, NV, Thuan, NX: Coupled fixed point theorems in partially ordered G-metric spaces. Math. Comput. Model. 55, 1601-1609 (2012)

30. Mohiuddine, SA, Alotaibi, A: On coupled fixed point theorems for nonlinear contractions in partially ordered G-metric spaces. Abstr. Appl. Anal. 2012, Article ID 897198 (2012)

31. Mustafa, Z, Sims, B: Fixed point theorems for contractive mappings in complete G-metric spaces. Fixed Point Theory Appl. 2009, Article ID 917175 (2009)

32. Tahat, N, Aydi, H, Karapinar, E, Shatanawi, W: Common fixed points for single-valued and multi-valued maps satisfying a generalized contraction in G-metric spaces. Fixed Point Theory Appl. 2012, 48 (2012)

doi:10.1186/1687-1812-2012-179

Cite this article as: Mohiuddine and Alotaibi: Some results on a tripled fixed point for nonlinear contractions in partially ordered G-metric spaces. Fixed Point Theory and Applications 2012 2012:179.

\section{Submit your manuscript to a SpringerOpen ${ }^{\ominus}$ journal and benefit from:}

- Convenient online submission

- Rigorous peer review

- Immediate publication on acceptance

- Open access: articles freely available online

- High visibility within the field

- Retaining the copyright to your article

Submit your next manuscript at $>$ springeropen.com 